\title{
Interactive Role of Metabolic Syndrome on the Pathogenesis and Severity of Breast Cancer, the Impact of Treatment Exposure
}

\author{
Safaa A Al-Zeidaneen* \\ Department of Pharmaconutrition, Al-Balqa Applied University, Jordan
}

\begin{abstract}
The evidence that link Metabolic Syndrome (MS) risks and Breast Cancer (BC) is highly controversial. This study was carried out to evaluate the MS among a group of newly and recently-diagnosed BC Jordanian women, according to harmonized criteria using the Jordanian cut-off points of obesity. A total of 396 BC patients aged 30-65 years attending BC clinics at the Jordanian Royal Medical Services in Jordan for management and follow-up of their conditions were screened for the presence of MS using the harmonized criteria. They were either newly-diagnosed before any medical intervention $(n=134)$ or recently-diagnosed who received medical intervention during the first 3 months of diagnosis $(n=262)$ BC patients. The latter were sub divided into chemo $(n=176)$ and non-chemo $(n=86)$ sub-groups. Pre-and postmenopausal status and BC severity [early stage $(n=189)$ and advanced stage $(n=207)$ ] of BC patients were also studied. The MS prevalence in the whole BC patients using harmonized cut-off points (64.1\%) was higher than that using Jordanian group cut-off points (52.0\%). The MS was more prevalent, but insignificant, in recently-diagnosed $(66.0 \%)$ than newly-diagnosed patients $(60.0 \%)$. The MS prevalence was associated with increased severity of BC; it was $67.1 \%$ in advanced stage and $60.8 \%$ in early stage. The risk of MS in postmenopausal BC patients was higher (34.8\%) than premenopausal (29.3\%) patients. The risk of MS was increased with age. According to aforementioned results, it could be concluded that MS was markedly prevalent among BC patients. The MS prevalence tended to be higher among recently-diagnosed than newly-diagnosed BC patients using the harmonized definition, however, this prevalence decreased when the Jordanian group cut-off points were used. The MS was more prevalent in postmenopausal than premenopausal BC patients and it was associated with increased BC severity.
\end{abstract}

Keywords: Breast cancer; Jordan cut-off points; Metabolic syndrome; Treatments exposure; Menopausal status; Cancer stage

\section{INTRODUCTION}

Breast Cancer (BC) is the most frequently occurring, life-threatening malignant tumour and the leading cause of cancer-related deaths among women worldwide [1]. In Jordan, BC ranked first among cancers in females, accounting for about $37 \%$ of all female cancers, a figure that agrees with that obtained from different countries in the region [2-4]. There are different types of $\mathrm{BC}$ treatment that currently used for BC therapy. The standard BC treatment approaches can be divided to local treatments, for localized small area of the body as surgery and radiation, and systemic treatments as chemotherapy, biological and hormonal, depending on the goal of treatment, type of BC and expected side effects [4]. Although many risk and prognostic factors of BC have been documented, an insight view of BC pathogenesis, severity and prognosis is still not clarified [5]. Evidence is now emerging on the possible role of the Metabolic Syndrome (MS) in the risk, progress and prognosis of the disease [6]. The available definitions of MS, although agree upon presence of at least three abnormalities among central obesity, hypertension, glucose intolerance and dyslipidemia, differ in the diagnosis of central obesity [7]. Cut-off values for diagnoses of central obesity using Waist Circumference (WC) and Waist to Hip Ratio (WHpR) in addition to Waist Circumference to Height Ratio (WHtR) are recently documented for Jordanians [8]. Although the relation between MS risk factors and BC risks have been suggested, the evidence is not consistent. There are few debatable studies that relate MS as a single entity with BC [9]. Several potential confounders might account for this controversy. However, there are no studies that assess MS in Jordanian or Arab $\mathrm{BC}$ patients or those that assess the relationship between $\mathrm{BC}$ and

Correspondence to: Safaa A Al-Zeidaneen, Assistant Professor of Pharmaconutrition, Al-Balqa Applied University, Jordan, Tel: +962796739802; E-mail: safaa84@bau.edu.jo

Received: April 22, 2019; Accepted: May 21, 2019; Published: June 11, 2019

Citation: Al-Zeidaneen SA (2019) Interactive role of Metabolic Syndrome on the Pathogenesis and Severity of Breast Cancer, the Impact of Treatment Exposure. J Biomol Res Ther 8: 179. doi: 10.35248/2167-7956.19.8.179

Copyright: (C) 2019 Al-Zeidaneen SA. This is an open-access article distributed under the terms of the Creative Commons Attribution License, which permits unrestricted use, distribution, and reproduction in any medium, provided the original author and source are credited. 
dietary intakes. Knowing that both $\mathrm{BC}$ and MS are products of the interaction between genetic and environmental risk factors and share many co-morbidities [10]. Understanding the biomarkers of each MS individual component and their relative contributions to $\mathrm{BC}$, may have implications in helping predict $\mathrm{BC}$ incidence and prognosis in terms of recurrence, pathogenesis, distal metastasis, and overall treatment outcome and patients quality of life. Considering that MS components are modifiable risk factors, thus primary and secondary preventive measures such as lifestyle and dietary modifications, can be suggested to reduce BC risks and improve its incidence or outcome $[9,10]$. Thus, the objectives of the present study were to: Evaluate the impact of treatments exposure on MS risk components using harmonized international definition and Jordanian cut-off point of obesity indices in accordance to age and stage in the studied BC Jordanian patients.

\section{MATERIALS AND METHODS}

\section{Study sample and design}

In this study, 396 Jordanian BC patients aged 30-65 years attending $\mathrm{BC}$ clinics at the Jordanian Royal Medical Services in Amman, Jordan for management and follow-up of their conditions during the period from January 2013 to February 2015 were screened for the presence of Metabolic Syndrome (MS) and its related risk factors. The experimental design permitted to include 134 newly-diagnosed BC patients who were not exposed to any type of treatment interventions and 262 recently-diagnosed BC patients during the first three months of being exposed to any type of treatment interventions. Recently group member were subdivided in two sub-groups to control exposure to chemotherapy. The experimental design also permitted to include pre- and postmenopausal BC patients for hormonal balance control. The patients were further divided according to BC stages into early stage and advanced stage as a measurement of BC severity [11,12]. The sample size (396) was statistically sound and accounts for about $50 \%$ of the BC cases in the year 2011 [3]. The median age of BC females in Jordan is 51 years, and about $80 \%$ of the diagnosed cases lied between the ages 35 and 65 years [2,3]. Newly and recently diagnosed BC women aged 30-65 years were included in the study. The patients were excluded if she had any clinical or laboratory evidence of cardiovascular disease, chronic renal failure, polycystic ovary syndrome thyroid disease, pregnancy and lactation. Any subject did not fit the inclusion criteria were excluded. Subjects below 30 or above 65 years of age, type I diabetes mellitus, epilepsy and those taking medical herbs were also excluded. This study was conducted according to the Declaration of Helsinki (2008, including 2013 amendments) and written informed consent was obtained from all participants at the start of the study. The Royal Medical Services Ethical Committee approved this study (reference number 1/2013).

\section{Data collection}

A questionnaire which included personal information, health, anthropometric and biochemical measurements was used for data collection. The medical specialist filled basic medical information about BC.

Anthropometric measurements: Anthropometric indicators including height, weight, WC were measured in duplicates with subjects lightly clothed and without shoes. These indicators were performed by the investigator following the methodological protocol described by Lee and Nieman [13]. Height was measured to the nearest $1.0 \mathrm{~mm}$ using a wall-mounted stadiometer and weight to the nearest $0.1 \mathrm{~kg}$ using an electronic scale.

Biochemical analyses: The fasting blood samples were collected then the plasma had been harvested and stored at $-80{ }^{\circ} \mathrm{C}$ for analysis. Biochemical analyses were carried out in Princess Eman Center for Laboratory Research and Science. The following laboratory measurements of Fasting Blood Glucose (FBG), lipid profile including Triglyc ־erides (TG) and High Density Cholesterol (HDL-C) were performed using colorimetric determination [14].

Blood pressure: Blood pressure was measured by a licensed staff nurse, twice using a standard mercury sphygmomanometer after seating the subjects for at least 15 minutes. The average value was recorded [13].

\section{Definition of the metabolic syndrome}

The harmonized criteria were used for the diagnosis of MS (7), which required the presence of at least three of the following risk components in $\mathrm{BC}$ women: elevated waist circumference $(>88 \mathrm{~cm})$, elevated triglycerides $(\geq 150 \mathrm{mg} / \mathrm{dl})$, reduced HDL-C $(<50 \mathrm{mg} / \mathrm{dl})$, elevated systolic blood pressure (SBP) or diastolic blood pressure (DPB) $(\geq 130 / 85 \mathrm{~mm} \mathrm{Hg})$, elevated fasting blood glucose $(\geq 100$ $\mathrm{mg} / \mathrm{dl})$. The documented Jordanian group cut-off point of waist circumferences (WC) for the diagnosis central obesity was used in the diagnosis of MS in the studied sample [8]. The latter value for women was $95.6 \mathrm{~cm}$.

\section{Statistical analysis}

Statistical analyses were performed using Statistical Package for the Social Sciences (SPSS), version 10.0 (SPSS Inc., Chicago, USA). Differences were significant at $\mathrm{p}<0.05$. Results were expressed according to the study needs as frequency distribution with their percentages (\%). Frequency distribution and percentages was performed for the health characteristics, prevalence of MS according to treatment exposure using Jordanian and international harmonized definition of MS. The prevalence of MS risk compare early and advanced BC stage or menopausal status according to study groups was also analysed.

\section{RESULTS}

Frequency distributions of metabolic syndrome risk factors according to treatment exposure are indicated in Table 1. Most of the BC patients had two $(23.5 \%)$ or three $(35.6 \%)$ metabolic syndrome (MS) risk factors using the harmonized criteria, which were significantly different $(\mathrm{p}<0.05)$ from those without MS risk factor $(2.8 \%)$ or had only one MS risk factor $(9.6 \%)$ or had four MS risk factors (16.2\%) and had five MS risk factors $(12.4 \%)$. Similar pattern of frequency distribution of MS risk factors was also observed in newly-diagnosed and recently-diagnosed chemo and non-chemo groups. Frequency distributions of MS risk factors were not significantly different $(\mathrm{p} \geq 0.05)$ according to treatment exposure groups Table 1. The prevalence of MS and its risk components in the study sample using the harmonized and the Jordanian group cut-off points by treatment exposure are exhibited in Table 1. The prevalence of MS in the whole sample using harmonized cut-off points $(64.1 \%)$ was significantly higher $(\mathrm{p}<0.05)$ than Jordanian group cut-off points $(52.0 \%)$. These significant 
Table 1: Frequency distribution of metabolic syndrome risk factors according to treatment exposure.

1. Values are given as number of patients $(\mathrm{n})$ and their percentages out of $(\mathrm{N})$.

2. Values in columns with different superscripts are significantly different $(\mathrm{p}<0.05)$. None of values in rows shows significant.

3. Abbreviations and definitions: newly- diagnosed: breast cancer patients who are not exposed to any type of interventions; recently- diagnosed: breast cancer patients within 3 months of diagnosis who are either exposed (chemo) or not exposed (non- chemo) to chemical therapy; metabolic syndrome (MS) was defined as the presence of three or more risks [7].
Numbers of MS risk

\begin{tabular}{ccccccccccccc}
\hline & $\mathrm{n}$ & $\%$ & & $\mathrm{n}$ & $\%$ & $\mathrm{~N}$ & $\%$ & $\mathrm{n}$ & $\%$ & $\mathrm{n}$ & $\%$ & \\
\hline 0 & 7 & & $5.2 \mathrm{a}$ & 1 & $1.2 \mathrm{a}$ & 3 & $1.7 \mathrm{a}$ & 4 & $1.5 \mathrm{a}$ & 11 & $2.8 \mathrm{a}$ \\
\hline 1 & 13 & $9.7 \mathrm{a}$ & 7 & $8.1 \mathrm{a}$ & 18 & $10.2 \mathrm{a}$ & 25 & $9.5 \mathrm{a}$ & 38 & $9.6 \mathrm{a}$ \\
\hline 2 & 33 & $24.6 \mathrm{~b}$ & 20 & $23.3 \mathrm{~b}$ & 40 & $22.7 \mathrm{~b}$ & 60 & $22.9 \mathrm{~b}$ & 93 & $23.5 \mathrm{~b}$ \\
\hline 3 & 54 & $40.3 \mathrm{~b}$ & 33 & $38.4 \mathrm{~b}$ & 54 & $30.7 \mathrm{~b}$ & 87 & $33.2 \mathrm{~b}$ & 141 & $35.6 \mathrm{~b}$ \\
\hline 4 & 14 & $10.4 \mathrm{a}$ & 16 & $18.6 \mathrm{a}$ & 34 & $19.3 \mathrm{a}$ & 50 & $19.1 \mathrm{a}$ & 64 & $16.2 \mathrm{a}$ \\
\hline 5 & 13 & $9.7 \mathrm{a}$ & 9 & $10.5 \mathrm{a}$ & 27 & $15.3 \mathrm{a}$ & 36 & $13.7 \mathrm{a}$ & 49 & $12.4 \mathrm{a}$ \\
\hline
\end{tabular}

differences in MS prevalence were also observed among all study groups. Similarly, the frequency of abnormal WC according to the harmonized $(81.6 \%)$ cut-off point was higher than Jordanian group cut-off points $(62.6 \%)$ in the whole sample and also in each of the study groups. The prevalence of elevated SBP $(\geq 130 \mathrm{~mm}$ $\mathrm{Hg}$ ) was significantly $(\mathrm{p}<0.05)$ higher in chemo group $(19.3 \%)$ than non-chemo $(9.3 \%)$ and newly-diagnosed (10.4\%) groups. The prevalence of increased TG $(\geq 150 \mathrm{mg} / \mathrm{dL})$ and TC $(\geq 200 \mathrm{mg} / \mathrm{dL})$ were more frequent $(\mathrm{p}<0.05)$ in recently-diagnosed group $(82.4 \%$ vs. $80.9 \%$ ) than in newly-diagnosed patients $(76.1 \%$ vs. $67.2 \%)$ for TG and TC respectively. The prevalence of low HDL-C ( $<50 \mathrm{mg} /$ $\mathrm{dL})$ was higher $(\mathrm{p}<0.05)$ in non-chemo group $(81.4 \%)$ than chemo $(63.6 \%)$ and newly-diagnosed (61.2\%) groups. The prevalence of increased DBP (18.4\%) and FBG (32.1\%) were not significantly different $(p \geq 0.05$ ) within study groups (Table 2$)$. Comparison of the prevalence of MS as diagnosed by the harmonized and the Jordanian group cut-off points in the study sample according to age and treatment exposure are shown Table 3. According to harmonized and Jordanian group cut-off points, the MS risk was respectively more prevalent $(\mathrm{p}<0.05)$ in $41-50$ years $(24 \%$ vs. $18.2 \%)$ and $>60$ years $(18.2 \%$ vs. $17.2 \%)$ age groups than in $51-60$ years $(15.4 \%$ vs. $12.6 \%)$ and $30-40$ years $(6.6 \%$ vs. $4.0 \%)$. The prevalence of MS risk using the harmonized cut-off points was significantly higher $(\mathrm{p}<0.05)$ than Jordanian group cut-off points in all study groups and age categories with exception of the age group $>60$ years. In this respect, the difference between the harmonized and the Jordanian group cut-off points was not significant ( $p$ $\geq 0.05)$. None of the age categories was significantly different ( $p \geq 0.05)$ among study groups (Table 3$)$. The risk of metabolic syndrome in early and advanced BC stage according to treatment exposure is indicated (Table 4). In the whole sample, prevalence of MS risk according to harmonized criteria advanced stage $\mathrm{BC}$ was more prevalent $(p<0.05)$ than early stage BC $(67.1 \%$ vs. $60.8 \%)$ respectively. Similar pattern of MS risk was also observed by using the Jordanian group cut-off points $(56.05 \%$ vs. $47.8 \%)$ for early and advanced stage BC respectively and it was significantly lower than $(p<0.05)$ that found by harmonized definition. The prevalence of metabolic risk according to BC stage was not significantly different ( $p \geq 0.05$ ) with respect to type of treatment exposure (Table 4). The risk of metabolic syndrome in pre and postmenopausal women according to treatment exposure is shown Table 5 . The prevalence of MS risk according to harmonized criteria was significantly higher $(\mathrm{p}<0.05)$ compared with Jordanian group cut-off points. The risk of MS using the Harmonized criteria was more prevalent in postmenopausal (34.8\%) than premenopausal (29.3\%) BC patients. Similar pattern of MS risk was also observed by using the Jordanian group cut-off points. The prevalence of metabolic risk factors in premenopausal and postmenopause patients was not significantly different $(\mathrm{p} \geq 0.05)$ with respect to type of treatment exposure (Table 5).

\section{DISCUSSION}

Thorough search in the literature revealed inconsistent evidence in studies regarding the link between Breast Cancer (BC) and Metabolic Syndrome (MS) risk components [6,10,15-18]. Studies in Jordan in this respect are limited and few epidemiological records are documented by the Ministry of Health [3]. Up to our knowledge, there are no studies that assess MS in Jordanian or in Arab BC patients in relation to age categories or BC stages. None of the reported studies have investigated MS risk factors in the newly and recently diagnosed BC patients. Studies that deal with $\mathrm{BC}$ type of treatment exposure and its relation with MS risk factors are also not available. Metabolic syndrome has a great interest worldwide because of its increasing prevalence, which varies within and across different populations [19]. In Jordan, Al-Odat et al. [8] in a study of 500 participants from both gender aged between 20 and 85 years. They have found that, MS prevalence according to IDF criteria was $44.0 \%$ with higher prevalence in men than in women and it was directly associated with age [20]. In another study, Khader et al. in north Jordan have reported that MS prevalence based on NCEP: ATP III criteria was $43.7 \%$ and it was more prevalent in women [21,22]. High prevalence of MS in Jordanian women was also reported by two other studies $[23,24]$. 
Table 2: Prevalence of metabolic syndrome and its risk factors in the study sample using the harmonized and Jordanian group cut-off points by treatment exposure [1-5].

1. Metabolic syndrome is defined as the presence of three or more risks, harmonized cutoff points: Alberti et al. (7); Jordanian cut-off points: AL-Odat et al. [8].

2. Values are given as number of patients $(\mathrm{n})$ and their percentages out of $(\mathrm{N})$.

3. Values in rows with different superscripts are significantly different $(\mathrm{p}<0.05)$.

4. $(\alpha)$ Significant difference $(\mathrm{p}<0.05)$ between Jordanian and international cut-off points.

5. Abbreviations and definitions: newly- diagnosed: breast cancer patients who are not exposed to any type of interventions; recently- diagnosed: breast cancer patients within 3 months of diagnosis who are either exposed (chemo) or not exposed (non- chemo) to chemical therapy; WC: waist circumferences cm; SBP: Systolic Blood Pressure; DBP: Diastolic Blood Pressure; FBG: Fasting Blood Glucose; TG: Triglycerides; HDL-c: High Density Lipoprotein; MS: Metabolic Syndrome.

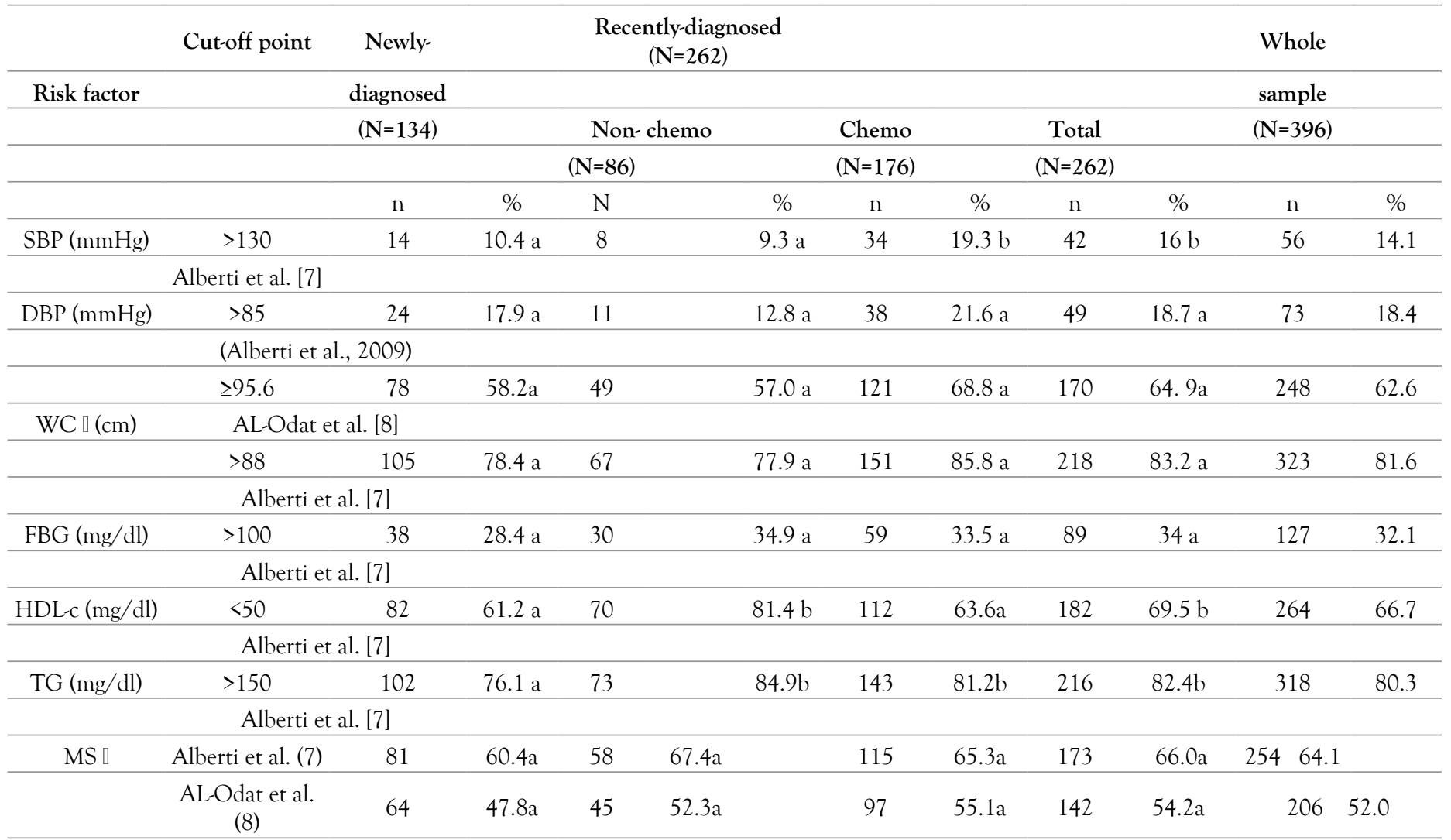

Several studies have reported MS prevalence among Arab population groups. In a random study of 542 Arab Americans aged between 20-75 years, the prevalence of MS was found to be $22.6 \%$ and $28.0 \%$ using the NCEP: ATP III and the WHO criteria respectively $[22,25,26]$. The prevalence of MS among Palestinians was $17.0 \%$ using the WHO criteria [26,27]. Among Omanis, the MS prevalence was $21.0 \%$ using NCEP: ATP III criteria $[22,28]$. Whereas, among Tunisians, it was $45.5 \%, 28.7 \%$ and $24.3 \%$ using IDF, WHO and NCEP: ATP III criteria respectively, with higher prevalence in women than men $[20,22,26,29]$. The MS prevalence was less than $2 \%$ in urban area of Sub-Saharan Africans using NCEP: ATP III criteria [22,30,31]. The prevalence of MS in developed countries using NCEP: ATP III criteria was $22.0 \%$ in United States 35.0\% in Canada and 22.1\% in Australia [22,32,33]. The considerable variations in the prevalence of MS across populations may be due to the interaction between genetics and environmental factors such as sedentary life style and obesity [21] or as a result of ethnicity $[20,30]$ or due to the use of different MS criteria [29]. This study showed that $64.1 \%$ of the Jordanian BC patients aged 30-65 years with no more than three months since diagnosis have MS using the harmonized criteria which is higher compared with the aforementioned studies [7]. The variation in the MS prevalence between the findings of this study and the previous studies may be due to differences in the MS criteria, study design, population size, and target group and age category. To the best of our knowledge, studies that investigate the prevalence of MS and its risk components in relation to age, stage, menopausal status and type of treatment exposure among BC patients in Jordan and Arab, are not available. In the current study, the prevalence of MS was found to be $60.4 \%$ in the newly-diagnosed BC patients and $66.0 \%$ in the recently-diagnosed $\mathrm{BC}$ patients when harmonized criteria were used. The prevalence decreased significantly $(47.8 \%$ in the newly-diagnosed BC patients and $54.2 \%$ in the recentlydiagnosed BC patients) using the reported Jordanian group cut-off points [8]. Differences in the results of the two definitions could be due to the difference in cut-off points in WC between the two criteria. The higher WC cut-off points of the Jordanian group definition, compared to that of harmonized definition could lead to the observed decreased MS prevalence. This is consistent with IDF criteria of MS which recommend the use of population estimates of WC cut-off points for measuring central obesity considering varies MS prevalence across different populations $[8,19,20]$. Worldwide, several studies have investigated the BC risk in relation to $\mathrm{MS}$ as a single entity condition [6,14-16]. The 
Table 3: Comparison of the prevalence of metabolic syndrome as diagnosed by the harmonized and the Jordanian group cut-off points in the study sample by age and treatment exposure [1-6].

1. Harmonized cut-off points: [7-8].

2. Values are given as number of patients $(\mathrm{n})$ and their percentages out of $(\mathrm{N})$.

3. $(\alpha)$ Significantly $(p<0.05)$ different between Jordanian and international cut-off points for each treatment exposure and whole sample.

4. Cross differences between treatments exposure groups were not significant $(\mathrm{p} \geq 0.05)$.

5. Values in columns with different superscripts are significantly different $(\mathrm{p}<0.05)$ with respect to age groups.

6. Abbreviations and definitions: newly-diagnosed: breast cancer patients who are not exposed to any type of interventions; recently-diagnosed: breast cancer patients within 3 months of diagnosis who are either exposed (chemo) or not exposed (non- chemo) to chemical therapy; MS: Metabolic Syndrome.

\begin{tabular}{|c|c|c|c|c|c|c|c|c|c|c|c|}
\hline \multirow[b]{2}{*}{ Age } & \multicolumn{3}{|c|}{ New-diagnosed $(\mathrm{N}=134)$} & \multicolumn{2}{|c|}{$\begin{array}{c}\text { Recently-diagnosed } \\
(\mathrm{N}=262)\end{array}$} & \multirow[b]{2}{*}{ Chemo } & \multirow{2}{*}{\multicolumn{2}{|c|}{ Total }} & & \multicolumn{2}{|c|}{$\begin{array}{l}\text { Whole sample } \\
\quad(\mathrm{N}=396)\end{array}$} \\
\hline & MS risk & & & Non-chemo & & & & & & & \\
\hline \multirow[t]{2}{*}{ (years) } & & & & $(\mathrm{N}=86)$ & & $(\mathrm{N}=176)$ & & $(\mathrm{N}=262)$ & & & \\
\hline & & $\mathrm{n}$ & $\%$ & $\mathrm{~N}$ & $\%$ & $\mathrm{n}$ & $\%$ & $\mathrm{n}$ & $\%$ & $\mathrm{n}$ & $\%$ \\
\hline \multirow[t]{2}{*}{$(30-40)$} & $\begin{array}{c}\text { Alberti et al. } \\
{[7][}\end{array}$ & 7 & $5.2 \mathrm{a}$ & 4 & $4.7 \mathrm{a}$ & 15 & $8.5 \mathrm{a}$ & 19 & $7.3 \mathrm{a}$ & 26 & $6.6 \mathrm{a}$ \\
\hline & $\begin{array}{l}\text { AL-Odat et } \\
\text { al. [8] }\end{array}$ & 4 & $3.0 \mathrm{a}$ & 2 & $2.3 \mathrm{a}$ & 10 & $5.7 \mathrm{a}$ & 12 & $4.6 \mathrm{a}$ & 16 & $4.0 \mathrm{a}$ \\
\hline \multirow[t]{2}{*}{$(41-50)$} & Alberti et al. [7] & 28 & $20.9 \mathrm{~b}$ & 26 & $30.2 \mathrm{~b}$ & 41 & $23.3 \mathrm{~b}$ & 67 & $25.6 \mathrm{~b}$ & 95 & $24.0 \mathrm{~b}$ \\
\hline & $\begin{array}{l}\text { AL-Odat et } \\
\text { al. [8] }\end{array}$ & 23 & $17.2 \mathrm{~b}$ & 17 & $19.8 \mathrm{~b}$ & 32 & $18.2 \mathrm{~b}$ & 49 & $18.7 \mathrm{~b}$ & 72 & $18.2 \mathrm{~b}$ \\
\hline \multirow[t]{2}{*}{$(51-60)$} & Alberti et al. [7] & 22 & $16.4 \mathrm{c}$ & 14 & $16.3 \mathrm{c}$ & 25 & $14.2 \mathrm{c}$ & 39 & $14.9 \mathrm{c}$ & 61 & $15.4 \mathrm{c}$ \\
\hline & $\begin{array}{l}\text { AL-Odat et } \\
\quad \text { al. [8] }\end{array}$ & 15 & $11.2 \mathrm{c}$ & 13 & $15.1 \mathrm{c}$ & 22 & $12.5 \mathrm{c}$ & 35 & $13.4 \mathrm{c}$ & 50 & $12.6 \mathrm{c}$ \\
\hline \multirow[t]{2}{*}{$(>60)$} & Alberti et al. [7] & 24 & $17.9 \mathrm{~b}$ & 14 & $16.3 \mathrm{c}$ & 34 & $19.3 \mathrm{~b}$ & 48 & $18.3 \mathrm{~b}$ & 72 & $18.2 \mathrm{~b}$ \\
\hline & $\begin{array}{l}\text { AL-Odat et } \\
\text { al. [8] }\end{array}$ & 22 & $16.4 b$ & 13 & $15.1 \mathrm{c}$ & 33 & $18.8 b$ & 46 & $17.6 \mathrm{~b}$ & 68 & $17.2 \mathrm{~b}$ \\
\hline \multirow[t]{2}{*}{ Total } & Alberti et al. [7] & 81 & 60.4 & 58 & 67.4 & 115 & 65.3 & 173 & 66 & 254 & 64.1 \\
\hline & $\begin{array}{l}\text { AL-Odat et } \\
\text { al. [8] }\end{array}$ & 64 & 47.8 & 45 & 52.3 & 97 & 55.1 & 142 & 54.2 & 206 & 52.0 \\
\hline
\end{tabular}

Table 4: The risk of metabolic syndrome in early and advanced BC stage according to treatment exposure [1-5].

1. Values are given as number of patients $(\mathrm{n})$ and their percentages out of $(\mathrm{N})$.

2. $\left(^{*}\right)$ Significant differences $(\mathrm{p}<0.05)$ between early and advanced stage breast cancer for treatment exposure groups.

3. $(\alpha)$ Significantly $(p<0.05)$ different between Jordanian and international cut-off points for each treatment exposure and whole sample.

4. Abbreviations and definitions: newly-diagnosed: breast cancer patients who are not exposed to any type of interventions; recently-diagnosed: breast cancer patients within 3 months of diagnosis who are either exposed (chemo) or not exposed (non- chemo) to chemical therapy; BC: Breast Cancer; early stage: early stage: stage I and II, advanced stage: III and IV; MS: Metabolic Syndrome.

5. Breast cancer stages (I-IV) according to Tumor size (T), Lymph Node Involvement (N), Metastasis (M) Classification System(TNM), Stage was classified as stage I (TO/T1 and N0), stage II (T0/T1 and N1, or T2 and N0/N1, or T3/N0), stage III (T0/T1/T2 and N2, or T3 and N1/N2, or T4 and any N, or any $\mathrm{T}$ and N3), stage IV (any T, any N, M1) according to Bloom and Richardson, Sobin and Wittekind [11,12].

\begin{tabular}{|c|c|c|c|c|c|c|c|}
\hline \multirow[t]{2}{*}{ MS risk } & \multicolumn{2}{|c|}{ Newly-diagnosed ( $\mathrm{N}=134)$} & \multicolumn{2}{|c|}{ Recently-diagnosed $(\mathrm{N}=262)$} & \multicolumn{3}{|c|}{ Whole sample $(\mathrm{N}=396)$} \\
\hline & Early stage & Advanced stage $(\mathrm{N}=20)$ & Early stage & Advanced stage $(\mathrm{N}=187)$ & Early stage & $(\mathrm{N}=189)$ & Advanced stage $(\mathrm{N}=207)$ \\
\hline & $(\mathrm{N}=114)$ & & $(\mathrm{N}=75)$ & & & & \\
\hline MS* $*$ Alberti et al. [7] & $\mathrm{n} \quad \%$ & $\%$ & $\%$ & $\%$ & $\mathrm{n}$ & $\%$ & $\%$ \\
\hline & 7061.8 & 1154.9 & 4560.0 & $128 \quad 68.4$ & 115 & 60.8 & 13967.1 \\
\hline $\mathrm{MS}^{*}$ & $54 \quad 47.3$ & $10 \quad 50.0$ & $36 \quad 47.8$ & 10656.7 & 90 & 47.8 & $116 \quad 56.05$ \\
\hline
\end{tabular}

(AL-Odat et al. [8].

association between MS as single entity and BC risk was first suggested by Kabat et al. [15]. In a longitudinal study of 165 BC patients, a modest positive association of postmenopausal BC with MS in time dependent analysis has been found. According to a prospective study by Healy et al. the prevalence of MS in newly diagnosed Irish women has been found to be almost 39\% and it is associated with more aggressive tumor phenotype [16]. In another prospective study consisting of 163 Italian $\mathrm{BC}$ women, the prevalence of MS has been reported to be $29.8 \%$ [6]. The prevalence of MS in this study was higher compared to previous studies. This high MS prevalence may be related to genetic or lifestyle factors such as eating habits and low physical activity, differences in MS criteria, sampling technique and sample size. In the present study, the MS risk tended to be more prevalent in recently-diagnosed BC patients than newly-diagnosed patients. This study was the first to investigate the MS risk in recently- and newly-diagnosed BC 
Table 5: The risk of metabolic syndrome in pre and postmenopause women according to treatment exposure [1-5].

1. Values are given as number of patients $(\mathrm{n})$ and their percentages out of $(\mathrm{N})$.

2. $\left(^{*}\right)$ Significantly $(\mathrm{p}<0.05)$ different between pre and postmenopausal women for each treatment exposure and whole sample.

3. Cross differences between treatment exposure groups were not significant $(\mathrm{p}>0.05)$.

4. $(\alpha)$ Significantly $(p<0.05)$ different between Jordanian and international cut-off points for each treatment exposure and whole sample.

5. Abbreviations and definitions: newly diagnosed: breast cancer patients who are not exposed to any type of interventions; recently diagnosed: breast cancer patients within 3 months of diagnosis who are either exposed (chemo) or not exposed (non- chemo) to chemical therapy; MS: metabolic syndrome.

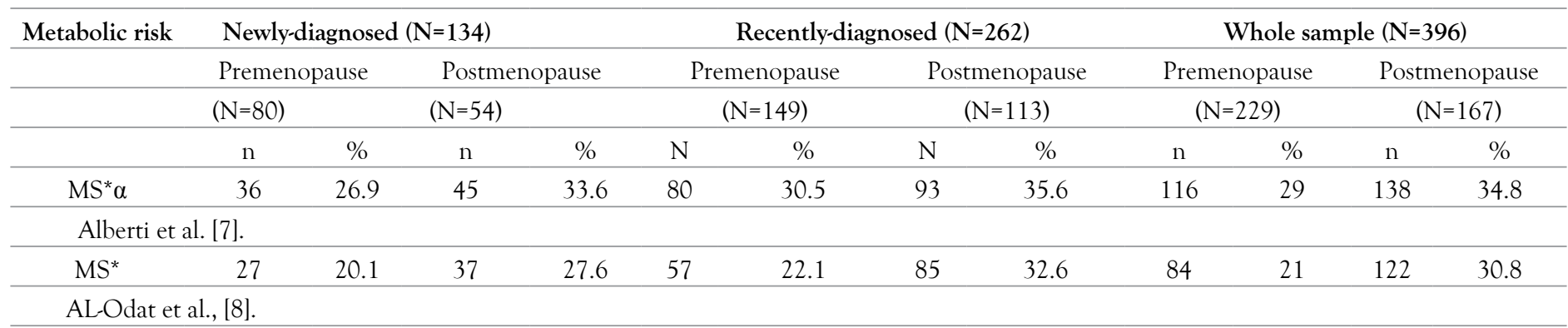

patients, the time limit between newly-and-recently diagnosed BC patients was up to three months of diagnosis, which may be insufficient to cause significant difference in MS risk. We suggest that, time since diagnosis may affect the MS risk. This coincide with a study by Kabat et al. where a modest positive association of $\mathrm{BC}$ with MS risk in time dependent analysis, after follow up for eight years, has been found, whereas, the association at baseline assessment has been absent [15]. The current study showed that MS was more prevalent in advanced stage (35\%) than early stage BC patients (29\%). This result is consistent with a study by Healy et al. where $45 \%$ of advanced stage BC patients had MS compared with 33\% for early stage disease [16]. In another study of $110 \mathrm{BC}$ women, MS has been associated with increased risk of recurrence and lower survival rate [34]. Low treatments response in BC patients with MS has been also reported [35]. In the current study, the MS risk was insignificantly different $(p \geq 0.05)$ between chemo and non-chemo BC patients. This study is the first to investigate the MS risk as single entity in non-chemo, exposed to surgical treatment only, and compared it with BC patients who exposed to chemotherapy. However, there is a recent study that has investigated the MS in BC patients, who received adjuvant chemotherapy, and found increased MS prevalence. These results were inconsistence with this study findings, the variation between results may be because the previous study has investigated the MS risk in BC patients taking chemotherapy after the 6th cycle as compared with the 1st cycle in addition to variations in the study size and design [36]. Most of MS studies have been conducted on postmenopausal BC women $[6,15,16]$. The MS risk in premenopausal women, defined as women below 50 years old, has been reported in a longitudinal study by Bjorge et al. [10]. The MS risk has been associated with a decreased risk of incident $\mathrm{BC}$ in premenopausal $\mathrm{BC}$ women with high $\mathrm{BMI}$ and with increased risk of BC mortality in postmenopausal women, above 60 years. This is consistent with present study, which showed a higher MS prevalence in postmenopausal (34.8\%) than premenopausal women (29.3\%). The suggested association between MS and postmenopausal BC risk may be as a result of age effect, insulin resistance or obesity associated with postmenopausal status [18]. In agreement with many studies, this study showed that MS prevalence was increased with age (Liu, 2006). The MS risk has been associated with increased BC mortality in women above 60 years [10]. This study showed increased MS risk from $6.6 \%$ in patients aged between $30-40$ years old to $18.2 \%$ in patients aged more than 60 years. This

J Biomol Res Ther, Vol. 8 Iss. 1 No. 179

ISSN: 2167-7956 increase in MS risk with age may be due to the age effect on menopausal status, insulin resistance and visceral fat accumulation [21]. The highest prevalence of MS risk was in $41-50$ years $(24.0 \%)$ age group. We suggest that, the high prevalence of MS in BC patients aged 41-50 years may be due to the high prevalence of MS risk components in this age group. According to aforementioned results, it could be concluded that MS was prevalent among BC patients. The MS prevalence was higher among recently-diagnosed than newly-diagnosed $\mathrm{BC}$ patients using the harmonized definition, however, this prevalence decreased when the Jordanian group cutoff points were used. The prevalence of MS was associated with increased BC severity and it was increased with age. This high prevalence of MS among study group may be lower than expected when using Jordanian cut-off points however; there is urgent need for careful medical care plan aimed to control the MS and associated risk factors among BC patients at national and international level.

\section{CONCLUSION}

\section{Strengths and limitations of the study}

To best of our knowledge, this study is the first in Jordan and perhaps in the Middle East that studies the interactive role of MS and its risk components on BC severity. This study is also the first in considering sampling $\mathrm{BC}$ patients according to type of treatment exposure and time since diagnosis. The study is limited by assessing the central obesity according to anthropometric measurements only, which does not differentiate between body tissue composition, bone, muscle and fat. This study is including $\mathrm{BC}$ patients at diagnosis or no more than three months later, therefore, it cannot estimate the lifestyle factors before and after that period.

\section{REFERENCES}

1. Jemal A, Siegel R, Ward E. Cancer statistics. CA Cancer J Clin. 2009;59:225-249.

\section{2. http://www.khcc.jo/section/jordan-breast-cancer-program}

3. Al-Tarawneh M, Arkoob K, Al-Nsour M. Epidemiology of breast cancer in women in Jordan: patient characteristics and survival analysis. EMH J. 2009;16:1032-1038.

4. https://www.cancer.org/cancer/breast-cancer.html 
5. Xue F, Michels KB. Diabetes, metabolic syndrome and breast cancer: a review of the current evidence. Am J Clin Nutr. 2007;86:s823-s835.

6. Agnoli C, Berrino F, Abagnato A. Metabolic syndrome and postmenopausal breast cancer in the ORDET cohort: a nested case-control study. Nutr Metab Cardiovasc Dis. 2010;20:41-48.

7. Alberti KG, Eckel RH, Grundy SM. Harmonizing the metabolic syndrome: a joint interim statement of the International Diabetes Federation Task Force on Epidemiology and Prevention; National Heart, Lung, and Blood Institute; American Heart Association; World Heart Federation; International Atherosclerosis Society; and International Association for the Study of Obesity. Circulation. 2009;120:1640-1645.

8. Al-Odat A, Ahmad MN, Haddad F. References of Anthropometric Indices of Central Obesity and Metabolic Syndrome in Jordanian Men and Women. Diabetes Metab Syndrome: Clin Res Rev. 2012;6:15-21.

9. Colonna SV, Douglas Case L, Lawrence JA. A retrospective review of the metabolic syndrome in women diagnosed with breast cancer and correlation with estrogen receptor. Breast Cancer Res Treat. 2012;131:325-331.

10. Bjorge T, Lukanova A, Jonsson H. Metabolic syndrome and breast cancer in the me-can (metabolic syndrome and cancer) project. Cancer Epidemiol Biomarkers Prev. 2010;19:1737-1745.

11. Bloom HJ, Richardson WW. Histological grading and prognosis in large study with long-term follow-up. Histopathology. 1957;19:403-410.

12. Sobin LH, Wittekind C. TNM classification of malignant tumors. UICC Wiley-Liss 2002.

13. Lee RD, Nieman DC. Nutrational Assessement. McGraw-Hill. 2010;5:34-35.

14. Burtis CA, Ashwood ER, Bruns DE. Tietz Textbook of Clinical Chemistry and Molecular Diagnostics. Elsevier, Saunders. 2006;4:101-105.

15. Kabat GC, Kim M, Chlebowski RT. A Longitudinal Study of the Metabolic Syndrome and Risk of Postmenopausal Breast Cancer. Cancer Epidemiol Biomarkers Prev. 2009;18:2046-2053.

16. Healy LA, Ryan AM, Rowley S. Obesity increases the risk of postmenopausal breast cancer and is associated with more advanced stage at presentation but no impact on survival. Breast J. 2010;16:95-97.

17. Rosato V, Bosetti C, Talamini R. Metabolic syndrome and the risk of breast cancer in postmenopausal women. Ann Oncol. 2011;22:2687-2692.

18. Esposito K, Chiodini P, Capuano A. Metabolic syndrome and postmenopausal breast cancer: systematic review and metaanalysis. Menopause. 2013;20:1301-1309.

19. Alberti KG, Zimmet PZ. Definition, diagnosis and classification of diabetes mellitus and its complications. Part 1: diagnosis and classification of diabetes mellitus provisional report of a WHO consultation. Diabet Med. 1998;15:539-553.

20. International Diabetes Federation. The IDF consensus worldwide definition of the metabolic syndrome. 2005.
21. Khader Y, Bateiha A, El-Khateeb M. High Prevalence of the metabolic syndrome among Northern Jordanians. J Diab Compl. 2007;21:214-219.

22. Executive Summary of the Third Report of the National Cholesterol Education Program (NCEP) Expert Panel on Detection, Evaluation and Treatment of High Blood Cholesterol In Adults (Adult Treatment Panel III). JAMA. 2001;285:2486-2497.

23. Obeidat AA, Ahmad MN, Haddad FH. Leptin and uric acid as predicstors of metabolic syndrome in Jordanian adults. Nutr Res Practv. 2016;10:411-417.

24. Yasein N, Ahmad M, Matrook F. Metabolic syndrome in patients with hypertension attending a family practice clinic in Jordan. East Mediterr Heal J. 2010;16:375-380.

25. World Health Organization (1999), Definition, Diagnosis and Classification of Diabetes Mellitus and its Complications. Report of a WHO Consultation. Part 1: Diagnosis and Classification of Diabetes Mellitus. Department of Noncommunicable Disease Surveillance. Geneva, Switzerland.

26. Jaber LA, Brown MB, Hammad A. The prevalence of the metabolic syndrome among Arab Americans. Diabet Care. 2004;27:234-238.

27. Abdul-Rahim HF, Husseini A, Bjertness E. The metabolic syndrome in the West Bank population: an urban-rural comparison. Diabetes Care. 2001;24:275-279.

28. Al-Lawati JA, Mohammed AJ, Al-Hinai HQ. Prevalence of the metabolic syndrome among Omani adults. Diabetes Care. 2003;26:1781-1785.

29. Harzallah F, Alberti H, Ben Khalifa F. The metabolic syndrome in an Arab population: a first look at the new International Diabetes Federation criteria. Diabetic Medicine. 2007;23:441-444.

30. Fezeu L, Balkau B, Kengne A. Metabolic syndrome in subSaharan African setting: central obesity may be the key determinant. Atherosclerosis. 2007;193:70-76.

31. Ford ES, Giles WH, Dietz WH. Prevalence of the metabolic syndrome among US adults: findings from the Third National Health and Nutrition Examination Survey. JAMA. 2002;287:356-359.

32. Liu J, Young K, Zinman B. Lifestyle variables, non-traditional cardiovascular risk factors, and the metabolic syndrome in an Aboriginal Canadian population. Obesity (Silver Spring). 2006;14:500-508.

33. Cameron J, Magliano J, Zimmet Z. The metabolic syndrome in Australia: prevalence using four definitions. Diabetes Res Clin Pract. 2007;77:471-478.

34. Pasanisi P, Berrino F, De Petris M. Metabolic syndrome as a prognostic factor for breast cancer recurrences. Int J Cancer. 2006;119:236-238.

35. Stebbins J, Sharma A, North B. A metabolic phenotyping approach to understanding relationships between metabolic syndrome and breast tumour responses to chemotherapy. Ann Oncol. 2012;23:860-866.

36. Bicakli DH, Varol U, Degirmenci M. Adjuvant chemotherapy may contribute to an increased risk for metabolic syndrome in patients with breast cancer. J Oncol Pharm Pract. 2014;21:317-318. 